\title{
Analisis Faktor Penyebab Kenyamanan dan Performance pada Siswi Ekstrakurikuler Lari Saat dalam Periode Menstruasi
}

\author{
Dian Maharani Widodo*, Supriyadi, Olivia Andiana \\ Universitas Negeri Malang, Jl. Semarang No. 5 Malang, Jawa Timur, Indonesia \\ *Penulis korespondensi, Surel: diianmaharanii2424@gmail.com
}

Paper received: 2-12-2021; revised: 20-12-2021; accepted: 28-12-2021

\begin{abstract}
This study is a survey research that aims to analyze the factors that cause comfort and performance in extracurricular running students of SMP Negeri 1 Kasembon. In this study using a quantitative approach. The sample consisted of running extracurricular students who were in their menstrual period totaling 15 students. Data collection in this study used a non-test instrument, namely a questionnaire. The data were tested using percentage calculations. Factors that affect the comfort and performance of students participating in extracurricular running at SMP Negeri 1 Kasembon during the menstrual period consist of physical and psychological factors.The results of the study based on the data obtained, factors that affect the comfort of female extracurricular participants running SMP Negeri 1 Kasembon during the menstrual period on average physical factors have a percentage of $75 \%$ and psychological factors $53.4 \%$. While Factors that affect the performance of extracurricular running students at SMP Negeri 1 Kasembon the average score from all aspects is 62.9 with the performance category being in the medium category, namely $100 \%$ (15 people).
\end{abstract}

Keywords: sprint; comfort; performance

\begin{abstract}
Abstrak
Penelitian ini merupakan penelitian survei yang bertujuan untuk menganalisis adanya faktor penyebab kenyamanan dan performance pada siswi ekstrakurikuler lari SMP Negeri 1 Kasembon. Pada penelitian ini menggunakan pendekatan kuantitatif. Sampel terdiri dari siswi ekstrakurikuler lari yang sedang dalam masa periode menstruasi berjumlah 15 siswi. Pengambilan data pada penelitian ini menggunakan Instrumen non tes yaitu dengan angket. Data diuji menggunakan perhitungan persentase. Faktor yang memengaruhi kenyamanan dan performance siswi peserta ekstrakurikuler lari SMP Negeri 1 Kasembon pada saat periode menstruasi terdiri dari faktor fisik dan psikis. Hasil penelitian berdasarkan data yang didapatkan, faktor yang memengaruhi kenyamanan siswi peserta ekstrakurikuler lari SMP Negeri 1 Kasembon pada saat periode menstruasi pada rata-rata faktor fisik memiliki persentase 75\% dan faktor psikis 53,4\%. Sedangkan faktor yang memengaruhi performance siswi peserta ekstrakurikuler lari SMP Negeri 1 Kasembon rata-rata skor dari seluruh aspek adalah 62,9 dengan kategori performance berada dalam kategori sedang yaitu $100 \%$ (15 orang).
\end{abstract}

Kata kunci: lari sprint; kenyamanan; performance

\section{Pendahuluan}

Menstruasi adalah sebuah proses yang terjadi secara alamiah yang umumnya dialami oleh para wanita dan merupakan salah satu tanda bahwa seseorang sudah mulai beranjak dewasa. Umumnya, pada usia 12-16 tahun remaja mengalami menstruasi (menarche). Pada saat menstruasi akan mengalami perubahan kejiwaan mental emosional yang tidak sesuai 
dengan perubahan organ-organ fisik secara cepat (Kumalasari, 2019). Seseorang yang sedang dalam masa menstruasi akan lebih malas melakukan kegiatan olahraga dikarenakan rasa nyeri yang akan ditimbulkan dari menstruasi, membuat anak-anak malas untuk berlari, melompat dan senam (Petiwi, 2011). Menurut penjelasan dari penelitian sebelumnya menerangkan bahwa saat dalam periode menstruasi dipengaruhi oleh faktor-faktor, ada faktor fisik dan psikis (Santrock, 2013). Menurut Hidayatul (2020) mengatakan bahwa, perilaku dari beberapa aspek seperti fisik, psikis dan lain-lain dipengaruhi oleh periode masa menstruasi. Salah satu aspek fisik dan psikis yang memengaruhi secara langsung pada menstruasi yaitu tingkat kenyamanan dan performance.

Kenyamanan merupakan kondisi kelegaan (kebutuhan telah tercapai)/ kebutuhan ketentraman (perasaan puas yang dapat meningkatkan penampilan) dan transenden (Wahid, 2016). Kenyamanan terbagi menjadi dua faktor yaitu fisik dan psikis. Pada kenyamanan fisik menurut (Yeni, 2017) : (1) Kenyamanan ruang, dalam hal ini berhubungan pada fungsi ruangan yang disesuaikan dengan antropometri tubuh manusia dan gerak tubuh manusia (2) Kenyamanan visual, peranan berasal dari fungsi masing-masing disesuaikan dengan kuantitas dan kualitas (3) Kenyamanan termal (Suhu), yaitu keadaan dimana manusia merasa tidak terganggu dengan keadaan lingkungan termal yang ada disekitarnya (4) Kenyamanan audial, dalam hal ini berhubungan dengan lingkungan (suara) yang mengganggu pendengaran.

Sedangkan yang didasarkan pada perasaan masing-masing individu adalah kenyamanan yang berasal dari psikis seseorang. Kenyamanan psikis adalah bentuk ekspresi yang timbul terhadap kondisi pikiran seseorang terhadap tingkat kepuasan seseorang pada lingkungannya. Sehingga proses sensasi kenyamanan dibutuhkan dalam usaha pengumpulan informasi tentang tingkat kenyamanan yang dirasakan. (Novziransyah, 2017) menjelaskan bahwa bagian awal dari proses persepsi keseluruhan merupakan pengertian umum dari proses sensasi. Sedangkan proses yang melibatkan proses penilaian, pemaknaan dan evaluasi lingkungan merupakan definisi dari proses persepsi secara tidak umum.

Banyak faktor yang memengaruhi performance seorang atlet. Faktor yang dimaksud yaitu berasal dari dalam dirinya (psikis) seperti : mood tidak bagus, kecemasan atau kenyamanan sedangkan dari luar diri (fisik) seperti : penonton, tempat pertandingan dan cuaca. Seorang atlet yang berada pada kondisi ideal yaitu dimana tidak hanya faktor psikis saja yang mendukung tetapi faktor fisik juga sangat diperlukan, hal ini bertujuan untuk mencapai performance yang maksimal.

Berdasarkan uraian yang telah dijelaskan menurut Dirgantari (2018) bahwa performance atlet dipengaruhi oleh 3 faktor yaitu, pelatih dan atlet mengharapkan kondisi ideal tetapi pada kenyataannya kondisi tersebut tidak sesuai dalam hal ini merupakan faktorfaktor yang ada dengan organisasi pertandingan, selanjutnya kebiasaan gaya hidup atlet, lingkungan sekitar dan faktor psikologis dari atlet dalam hal ini merupakan faktor-faktor yang berhubungan dengan atlet dan yang terakhir adalah berhubungan dengan latihan baik itu program yang diberikan dan juga pelatih dalam hal ini merupakan faktor-faktor yang berhubungan dengan latihan.

Berdasarkan pengamatan peneliti, bahwasanya kenyamanan dan performance siswi peserta ekstrakurkuler lari SMP Negeri 1 Kasembon saat dalam periode menstruasi dipengaruhi oleh faktor-faktor. Berdasarkan dari hal tersebut peneliti, melakukan penelitian 
dengan judul "Analisis Faktor Penyebab Kenyamanan Dan Performance Pada Siswi Ekstrakurikuler Lari Saat Dalam Periode Menstruasi”.

\section{Metode}

Metode yang digunakan adalah penelitian survei, dengan tujuan untuk menghasilkan informasi secara alami dan bersifat statistik (Adiyanta, 2019); serta dengan adanya pendekatan kuantitatif yang menganalisis faktor-faktor yang memengaruhi kenyamanan dan performance saat dalam periode menstruasi. Penelitian ini membutuhkan waktu 8 minggu dengan 6 kali pertemuan dan dilakukan saat siswi peserta ekstrakurikuler lari sedang dalam masa periode menstruasi. Sedangkan sampel penelitian adalah seluruh siswi ekstrakurikuler lari SMPN 1 Kasembon dengan jumlah 15 orang siswi yang sedang dalam masa periode menstruasi berkarakteristik; berusia 10-16 tahun.

Instrumen penelitian menggunakan instrumen non tes dengan angket. Data diambil dari hasil pengisian kuesioner oleh subjek sebagai sampel, yang dilakukan setelah kegiatan ekstrakurikuler lari di tempat latihan selesai pada saat siswi ekstrakurikuler lari sedang dalam masa periode menstruasi. Pengolahannya dengan menggunakan rumus:

$\frac{\mathrm{A}}{\mathrm{B}}=100$

\section{Keterangan :}

A = Frekuensi siswi yang diamati

$\mathrm{B}=$ Jumlah seluruh siswi yang menjadi responden

\section{Hasil dan Pembahasan}

Deskripsi data pada penelitian berasal dari hasil observasi dan angket yang didapatkan dari tes lari sprint siswi peserta ekstrakurikuler lari SMP Negeri 1 Malang saat dalam periode menstruasi. Berikut adalah tabel deskripsi data kenyamanan dan performance yang disajikan pada tabel berikut.

Tabel 1. Pertama Mengalami Menstruasi

\begin{tabular}{ccc}
\hline Usia & Frekuensi & Persentase \\
\hline$\leq 12$ Tahun & 5 & $33,3 \%$ \\
$12-14$ Tahun & 9 & $60 \%$ \\
$\geq 14$ Tahun & 1 & $6,7 \%$ \\
\hline
\end{tabular}

Pada tabel di atas menunjukkan hasil 5 orang $(33,3 \%)$ pertama kali mengalami menstruasi di usia kurang dari 12 tahun, 9 orang (60\%) mengalami menstruasi di usia 12 sampai 14 tahun dan 1 orang (6,7\%) mengalami menstruasi di usia lebih dari 14 tahun.

Tabel 2. Siklus Menstruasi

\begin{tabular}{ccc}
\hline Rentan Waktu & Frekuensi & Persentase \\
\hline$\leq 21$ hari & 3 & $20 \%$ \\
21 - 32 hari & 10 & $66,7 \%$ \\
$\geq 32$ hari & 2 & $13,3 \%$ \\
\hline
\end{tabular}

Pada tabel di atas menunjukkan hasil 3 orang (20\%) mengalami lama menstruasi pada bulan berikutnya kurang dari 21 hari, 10 orang $(66,7 \%)$ mengalami lama menstruasi pada 
bulan berikutnya terjadi antara hari 21 sampai 32 hari dan 2 orang $(13,3 \%)$ mengalami lama menstruasi pada bulan berikutnya lebih dari 32 hari.

Tabel 3. Lama Menstruasi

\begin{tabular}{ccc}
\hline Rentan Waktu & Frekuensi & Persentase \\
\hline 3 3 hari & 0 & $0 \%$ \\
3 - 7 hari & 13 & $86,7 \%$ \\
$\geq 7$ hari & 2 & $13,3 \%$ \\
\hline
\end{tabular}

Pada table 3, menunjukkan hasil 13 orang $(86,7 \%)$ mengalami masa menstruasi selama 3 sampai 7 hari dan 2 orang (13,3\%) mengalami masa menstruasi lebih dari 7 hari.

Tabel 4. Kenyamanan Kategori Fisik

\begin{tabular}{lcccc}
\hline \multicolumn{1}{c}{ Pernyataan } & \multicolumn{2}{c}{ Ya } & \multicolumn{2}{c}{ Tidak } \\
& (f) & (\%) & (f) & (\%) \\
\hline Nyeri dan pembengkakan pada payudara & 12 & $80 \%$ & 3 & $20 \%$ \\
Merasa marah atau temperamental & 11 & $73,3 \%$ & 4 & $26,7 \%$ \\
Perut terasa kembung & 8 & $53,3 \%$ & 7 & $46,7 \%$ \\
Nyeri punggung, nyeri sendi dan otot & 7 & $46,7 \%$ & 8 & $53,3 \%$ \\
Berat badan meningkat & 12 & $80 \%$ & 3 & $20 \%$ \\
Nyeri pada bagian perut & 11 & $73,3 \%$ & 4 & $26,7 \%$ \\
Bengkak pada pergelangan kaki & 12 & $80 \%$ & 3 & $20 \%$ \\
Terbiasa melakukan aktivitas fisik yang berat & 12 & $80 \%$ & 3 & $20 \%$ \\
Merasa mual, muntah dan pusing & 10 & $66,7 \%$ & 5 & $33,3 \%$ \\
\hline Rata-rata & & $75 \%$ & & $25 \%$ \\
\hline
\end{tabular}

Pada tabel di atas diketahui bahwa faktor fisik yang memengaruhi kenyamanan adalah nyeri dan pembengkakan pada payudara 12 orang $(80 \%)$, merasa marah atau tempramental 11 orang $(73,3 \%)$, perut terasa kembung 8 orang $(53,3 \%)$, berat badan meningkat 12 orang (80\%), nyeri pada bagian perut 11 orang $(73,3 \%)$, bengkak pada pergelangan kaki 12 orang $(80 \%)$, terbiasa melakukan aktivitas fisik yang berat 12 orang (80\%), merasa mual, muntah dan pusing 10 orang $(66,7 \%)$.

Tabel 5. Kenyamanan Kategori Psikis

\begin{tabular}{lcccc}
\hline \multicolumn{1}{c}{ Pernyataan } & Ya & \multicolumn{2}{c}{ Tidak } \\
& (f) & (\%) & (f) & (\%) \\
\hline Merasa tidak sanggup/mampu (tegang,gugup) & 7 & $46,7 \%$ & 8 & $53,3 \%$ \\
Merasa sedih atau murung & 9 & $60 \%$ & 6 & $40 \%$ \\
Kehilangan konsentrasi selama latihan & 7 & $46,7 \%$ & 8 & $53,3 \%$ \\
Mudah merasa kesal & 9 & $60 \%$ & 6 & $40 \%$ \\
Tidak sabaran & 6 & $40 \%$ & 9 & $60 \%$ \\
Tertekan & 10 & $66,7 \%$ & 5 & $33,3 \%$ \\
\hline Rata-rata & & $53,4 \%$ & & $46,7 \%$ \\
\hline
\end{tabular}

Dari hasil data tabel di atas diketahui bahwa faktor psikis yang memengaruhi kenyamanan adalah merasa sedih atau murung 9 orang (60\%), mudah merasa kesal 9 orang (60\%), tertekan 10 orang $(66,67 \%)$. 
Tabel 6. Hasil Kategori Performance dari Seluruh Aspek

\begin{tabular}{lcc}
\hline Responden & Total Skor & Kategori \\
\hline CNAP & 61 & Sedang \\
DR & 64 & Sedang \\
APNA & 69 & Sedang \\
ZLR & 62 & Sedang \\
SCK & 64 & Sedang \\
AMA & 65 & Sedang \\
W & 61 & Sedang \\
FF & 63 & Sedang \\
YPA & 61 & Sedang \\
RCL & 65 & Sedang \\
LS & 62 & Sedang \\
AD & 59 & Sedang \\
SR & 65 & Sedang \\
MCL & 58 & Sedang \\
SV & 65 & Sedang \\
\hline Rata-rata & 62,9 & Sedang \\
\hline
\end{tabular}

Berdasarkan dari hasil tabel di atas diketahui bahwa total skor yang didapatkan seluruh responden adalah 58-61 dengan rata-rata 62,9 dalam hal ini menunjukkan bahwa kategori performance dari seluruh aspek berada dalam kategori sedang.

Tabel 7. Hasil Persentase dan Frekuensi Performance

\begin{tabular}{lcc}
\hline Kategori & Frekuensi (f) & Persentase (\%) \\
\hline Tinggi & 0 & $0 \%$ \\
Sedang & 15 & $100 \%$ \\
Rendah & 0 & $0 \%$ \\
\hline
\end{tabular}

Berdasarkan data tabel di atas menunjukkan bahwa tingkat performance siswi peserta ekstrakurikuler lari SMP Negeri 1 Kasembon saat dalam periode menstruasi berada dalam kategori sedang yaitu 100\% (15 orang).

\subsection{Hasil Analisis Faktor Penyebab Kenyamanan Siswi Ekstrakurikuler Lari SMP Negeri 1 Kasembon Saat Dalam Masa Periode Menstruasi}

\subsubsection{Usia Menstruasi}

Pada usia 12-14 tahun, menarche atau menstruasi pertama umumnya terjadi. Namun, pada usia kurang dari 12 tahun terdapat beberapa kasus yang terjadi (Trimayasari, 2014). Dua faktor yang menyebabkan usia menarche cepat terjadi yaitu, faktor internal (psikis) seperti genetik yang turun temurun dan faktor eksternal (fisik) seperti asupan gizi, pola hidup dan status gizi (Santrock, 2013).

Berdasarkan analisis peneliti di lapangan diketahui bahwa siswi peserta ekstrakurikuler lari SMP Negeri 1 Kasembon 5 orang (33,33\%) pertama kali mengalami menstruasi di usia kurang dari 12 tahun, 9 orang (60\%) mengalami menstruasi di usia 12 sampai 14 tahun dan 1 orang $(6,7 \%)$ mengalami menstruasi di usia lebih dari 14 tahun. Data tersebut menunjukkan 
bahwa mayoritas siswi peserta ekstrakurikuler lari mengalami menstruasi ketika mereka berada pada usia 12 - 14 tahun.

Usia menarche dipengaruhi oleh faktor genetik, keadaan sosial ekonomi, massa tubuh, iklim, budaya, bangsa dan lain-lain (Mutasya, 2016). Menarche dipengaruhi oleh faktor internal (psikis) dan eksternal (fisik). Pada faktor (psikis) adalah : berhubungan dengan percepatan, perlambatan kejadian menarche dan status menarche remaja (genetik) dengan kejadian menarche ibunya. Sedangkan pada faktor (fisik) adalah : gaya hidup, keterpaparan media massa, nutrisi, sosial dan ekonomi ( Hastuti, 2017). Menurut Pratiwi (2017) mengatakan bahwa faktor suku, genetik, gizi, sosial dan ekonomi merupakan faktor yang memengaruhi usia mencapai menarche. Berdasarkan teori yang telah dijelaskan hasil analisis sesuai bahwa usia menarche atau menstruasi dipengaruhi oleh faktor-faktor yaitu ada faktor fisik dan psikis.

\subsubsection{Siklus Menstruasi}

Siklus menstruasi merupakan dimulainya menstruasi yang baru setelah menstruasi yang lalu dengan jarak antara tanggal sebagai pembatasnya (Ilmi, 2019). Menarche atau menstruasi diawali dengan sistem reproduksi seorang wanita yang sudah mulai berfungsi. Pada umumnya menstruasi normal terjadi 5-7 hari dan berlangsung 21-32 hari. Sedangkan pendarahan yang terjadi kurang lebih 3-5 hari dan ada yang 1-2 hari dengan diikuti darah yang sedikit-sedikit. Jumlah darah yang dikeluarkan 30-40 cc. Puncaknya dialami saat hari ke-2 atau ke-3 (Tsamara, 2020).

Hasil analisis peneliti dilapangan menunjukkan bahwa siswi peserta ekstrakurkuler lari SMP Negeri 1 Kasembon, 3 orang (20\%) mengalami siklus menstruasi pada bulan berikutnya kurang dari 21 hari, 10 orang $(66,66 \%)$ mengalami siklus menstruasi pada bulan berikutnya terjadi antara hari 21 sampai 32 hari dan 2 orang (13,34\%) mengalami siklus menstruasi pada bulan berikutnya lebih dari 32 hari. Dari data tersebut diketahui bahwa rata-rata siswi peserta ekstrakurikuler lari mengalami siklus menstruasi mayoritas 21 hari sampai 32 hari.

Menurut Latifah (2017) status psikologi mengakibatkan perubahan siklus menstruasi berhubungan dengan pola aktivitas fisik dan status gizi. Ketidakteraturan siklus menstruasi dipengaruhi beberapa faktor diantaranya yaitu sistem saraf, kadar hormonal, nutrisi, perubahan vaskularisasi dan psikologi (Benson, 2009). Menurut Simamora (2016) ketidakteraturan siklus menstruasi dipengaruhi faktor-faktor yaitu, faktor gizi buruk, aktivitas fisik, enzim vaskular, psikologi, penyakit kronis, hormone dan prostaglandin. Hasil analisis peneliti sesuai dengan teori yang menyatakan siklus menstruasi dipengaruhi oleh faktor fisik dan psikis.

\subsubsection{Lama Menstruasi}

Lama menstruasi merupakan kondisi ketika seorang sedang dalam masa menstruasi dengan mengeluarkan darah secara berturut-turut yang umumnya terjadi selama 3-7 hari. Menurut Indah (2020) lama menstruasi yang normal pada remaja adalah 3-7 hari. Setiap periode umumnya lama menstruasi berlangsung sekitar 3 sampai 6 hari. Namun sebagian orang ada juga yang mengalami menstruasi sampai 7 hari, Apabila setiap periode menstruasi terjadi berkala seperti itu maka dalam ini masih dianggap normal (Ginanjarsari, 2019). 
Hasil analisis peneliti dilapangan menunjukkan bahwa siswi peserta ekstrakurkuler lari SMP Negeri 1 Kasembon, 13 orang (86,75\%) mengalami masa menstruasi selama 3 sampai 7 hari dan 2 orang $(13,33 \%)$ mengalami masa menstruasi lebih dari 7 hari. Dari data tersebut diketahui bahwa rata-rata siswi peserta ekstrakurikuler lari mengalami lama menstruasi mayoritas 3 hari sampai 7 hari.

Menurut Sari (2018) faktor aktivitas fisik, faktor hormon, faktor makanan yang dikonsumsi, faktor genetik, masalah dalam vaskular dan lain-lain merupakan faktor yang berpengaruh terhadap lama menstruasi. Faktor psikis dan fisik merupakan faktor yang memengaruhi lama menstruasi. Pada faktor yang berkaitan dengan tingkat emosional remaja putri yang cenderung labil hal ini termasuk pada faktor psikis. Sedangkan faktor yang berkaitan dengan kontraksi otot uterus yang berlebih pada fase sekresi sehingga produksi hormon prostaglandin pun menjadi berlebih dalam hal ini termasuk pada faktor psikis (Pundati, 2016). Hasil analisis dalam penelitian ini sesuai dengan teori yang menyatakan bahwa lama menstruasi dipengaruhi faktor fisik dan psikis.

\subsubsection{Analisis Faktor Kenyamanan}

Kenyamanan atau rasa nyaman adalah suatu keadaan telah terpenuhinya kebutuhan dasar manusia yaitu kebutuhan akan kelegaan (kebutuhan telah tercukupi), transenden (sesuatu yang membuat masalah dan nyeri) dan ketentraman (suatu kepuasan yang meningkatkan penampilan sehari-hari (Wahid, 2016). Menurut Amsyar (2015) aspek kenyamanan dapat dipengaruhi oleh beberapa faktor yaitu : a) kenyamanan psikis, merupakan kenyamanan yang berkenaan dengan kesadaran internal diri, (b) kenyamanan fisik, merupakan jenis kenyamanan yang dapat dirasakan langsung oleh sensai setiap tubuh setiap orang berkenaan dengan lingkungan, kondisi dan pengaruh dari luar kepada manusia seperti temperatur, warna, suhu,pencahayaan,suara dll.

Hasil analisis peneliti dilapangan dari faktor penyebab kenyamanan pada peserta ekstrakurikuler lari SMP Negeri 1 Kasembon didapatkan hasil bahwa kenyamanan siswi peserta ekstrakurikuler lari faktor fisik yang memengaruhi kenyamanan adalah nyeri dan pembengkakan pada payudara 12 orang (80\%), merasa marah atau tempramental 11 orang $(73,3 \%)$, perut terasa kembung 8 orang $(53,3 \%)$, berat badan meningkat 12 orang $(80 \%)$, nyeri pada bagian perut 11 orang $(73,3 \%)$, bengkak pada pergelangan kaki 12 orang (80\%), terbiasa melakukan aktivitas fisik yang berat 12 orang (80\%), merasa mual, muntah dan pusing 10 orang $(66,7 \%)$. Sedangkan pada faktor psikis yang memengaruhi kenyamanan adalah merasa sedih atau murung 9 orang (60\%), mudah merasa kesal 9 orang (60\%), tertekan 10 orang $(66,7 \%)$. Berdasarkan hasil analisis faktor kenyamanan yang telah didapatkan bahwa rata-rata faktor fisik memiliki persentase $75 \%$ dan faktor psikis 53,4\% dalam hal ini menunjukkan bahwa faktor fisik dan psikis memengaruhi kenyamanan dan akan berdampak pada penurunan prestasi.

Pada penelitian ini membutuhkan lama penelitian selama 8 minggu dengan 15 responden. Dilakukan 6 kali pertemuan pada saat siswi dalam masa periode menstruasi. Berdasarkan analisis peneliti di lapangan diketahui bahwa kenyamanan siswi ekstrakurikuler lari SMP Negeri 1 Kasembon dipengaruhi oleh faktor fisik dan psikis. Menurut Cahyani (2017) pada interaksi faktor fisik dan psikis dapat memengaruhi kondisi kenyamanan suatu lingkungan. Menurut Auliciems (2017) kenyamanan dipengaruhi oleh beberapa faktor yakni 
usia, jenis kelamin, kondisi tubuh, temperatur udara, kelembaban udara, pergerakan angin, radiasi, faktor subjektif, seperti metabolisme dan bentuk tubuh. Faktor yang bersifat psikis diantaranya : kondisi pikiran, perasaan sedih atau murung,tertekan dll. Sementara yang bersifat fisik diantaranya : rasa sakit, kondisi fisik dan berat badan meningkat (Amsyar, 2015). Kenyamanan dalam melakukan aktivitas fisik dipengaruhi oleh faktor fisik dan psikis dan akan berdampak pada penurunan prestasi. Menurut Kuspriyani (2014) ketika atlet merasa tidak nyaman akan menyebabkan gangguan pada psikis yang akan berdampak pada fisik dan penurunan prestasi atlet. Kenyamanan atlet dipengaruhi oleh faktor fisik dan psikis yang berdampak pada penurunan prestasi atlet itu sendiri (Maulana, 2019).

\subsection{Hasil Analisis Faktor Performance Siswi Ekstrakurikuler Lari SMP Negeri 1 Kasembon Saat Dalam Masa Periode Menstruasi}

\subsubsection{Analisis Faktor Performance}

Performance atau performa dalam bahasa indonesia berarti sebuah kinerja atau sesuatu yang ingin didapatkan dan dicapai, sebuah prestasi yang diperlihatkan dan kemampuan seseorang. Sedangkan performa diartikan sebagai hal melakukan, menyelenggarakan, penampilan atau hal memainkan (Indraharsani, 2017). Performa pada atlet sepak bola dipengaruhi oleh faktor fisik dan psikis (Guntoro, 2020). Menurut Nideffer (2010) berpendapat faktor fisik dan psikis dapat memengaruhi. Ada hubungan antara aspek keterampilan dan aspek fisik dari atlet senam artistic (Firmansyah, 2017).

Hasil analisis peneliti dilapangan menggunakan perhitungan norma dari peneliti sebelumnya didapatkan hasil bahwa tingkat performance siswi peserta ekstrakurikuler lari SMP Negeri 1 Kasembon saat dalam periode menstruasi berada dalam kategori sedang yaitu $100 \%$ (15 orang). Sedangkan hasil penelitian yang telah didapatkan diketahui bahwa total skor yang didapatkan seluruh responden adalah 58-69 dengan rata-rata 62,9 dalam hal ini menunjukkan bahwa kategori performance siswi ekstrakurikuler lari dipengaruhi oleh faktor fisik dan psikis yang berpengaruh pada prestasi siswi SMP Negeri 1 Kasembon Malang.

Pada penelitian ini membutuhkan lama penelitian selama 8 minggu dengan 15 responden. Dilakukan 6 kali pertemuan pada saat siswi dalam masa periode menstruasi. Berdasarkan analisis peneliti yang dilakukan terdapat faktor yang memengaruhi performance siswi ekstrakurikuler lari SMP Negeri 1 Kasembon. Performance dipengaruhi oleh satunya faktor fisik dan psikis. Menurut Fakhrurri (2018) performance dipengaruhi oleh faktor fisik: (a) Terkendali, dalam kondisi ini atlet melakukan sesuatu sesuai apa yang diinginkannya (b) Fisik rileks, dalam kondisi ini atlet tidak merasakan adanya ketegangan atau kesulitan dalam melakukan suatu gerakan, (c) Berenergi tinggi, dalam kondisi ini atlet belum siap bertanding masih mencoba-coba melakukan serangan dan lain-lain, (d) Kesadaran tinggi, dalam kondisi ini atlet memiliki kesadaran yang tinggi tentang apa yang terjadi pada dirinya dan pada diri lawannya seperti peka terhadap perubahan posisi, serangan, pertahanan dan sebagainya, sedangkan faktor psikis terdiri dari (a) Terselubung (terlindungi dari gangguan) dalam kondisi maksudnya ini atlet menjadi lebih mudah mengakses keterampilan psikologisnya dan menyingkirkan berbagai kendala psikofisik (b) Mental rileks, kondisi ini dilukiskan sebagai kondisi ketenangan internal contohnya individu atau atlet tidak terburu-buru waktu untuk melakukan sesuatu, (c) Optimis, atlet merasa penuh percaya diri, yakin dengan apa yang dilakukannya akan membuahkan hasil 
sesuai dengan harapan, (d) Terpusat pada kekinian, atlet merasakan adanya keseimbangan psikofisik, segala sesuatu bekerja secara harmonis sebagai suatu kesatuan yang selaras dan berlangsung secara otomatis. Menurut Romas (2019) prestasi yang akan dicapai oleh atlet dipengaruhi oleh faktor-faktor yaitu melibatkan psikis berupa rasa percaya diri, komitmen, ketekunan, ketabahan, disiplin, tanggung jawab, motivasi, daya konsentrasi, relaksasi dan daya manajemen stress. Pola pikir psikis dan kondisi fisik mampu menyebabkan konsekuensi negatif berupa stres, kelelahan atlet dan penurunan kinerja (performa) yang akan berdampak pada penurunan prestasi atlet dan aspek fisik berupa ketangkasan fisik, berenergi tinggi (Sakar, 2017).

\section{Simpulan}

Kesimpulan dari penelitian ini adalah faktor yang memengaruhi kenyamanan siswi peserta ekstrakurikuler lari SMP Negeri 1 Kasembon pada saat periode menstruasi terdiri dari faktor fisik dan psikis. Pada rata-rata faktor fisik memiliki persentase $75 \%$ dan faktor psikis $53,4 \%$. Sedangkan faktor yang memengaruhi performance siswi peserta ekstrakurikuler lari SMP Negeri 1 Kasembon pada saat periode menstruasi terdiri dari faktor fisik dan psikis. Pada rata-rata skor dari seluruh aspek adalah 62,9 dengan kategori performance berada dalam kategori sedang yaitu 100\% (15 orang).

\section{Daftar Rujukan}

Adiyanta, F. C. S. (2019). Hukum dan Studi Penelitian Empiris: Penggunaan Metode Survey sebagai Instrumen Penelitian Hukum Empiris. Administrative Law and Governance Journal, 2(4), 697-709. https://doi.org/10.14710/alj.v2i4.697-709

Aridawarni, Y., \& Hastuti, D. W. (2017). Status GIZI dan FAKTOR KETURUNAN DENGAN USIA MENARCHE. Jurnal Obstretika Scientia, 5(2), 114-129.

Dirgantari. (2018). Mental Toughnes Dengan Peak Performance Pada Atlet Renang. Revista CENIC. Ciencias Biológicas, 152(3), 28.

Hidayatul, M., Supriyadi, S. (2020). Tingkat Stres Dan Aktivitas Fisik Berhubungan Dengan Siklus Menstruasi. Sekolah Tinggi Ilmu Kesehatan Kendal, $12(501$ - 512), 12.

Ilmi, A. F., \& Selasmi, E. W. (2019). Faktor-Faktor Yang Berhubungan Dengan Siklus Menstruasi Pada Remaja Putri Kelas XI di SMA Negeri 6 Tangerang Selatan. Edu Masda Journal, 3(2), 175. https://doi.org/10.52118/edumasda.v3i2.39

Indah, A. (2020). Efektivitas Relaksasi Benson terhadap Intensitas Nyeri Haid pada Mahasiswi Fakultas Keperawatan Universitas Sumatera Utara SKRIPSI oleh Indah Agustinia.

Indraharsani, I. A. S., \& Budisetyani, I. W. (2017). Efektivitas Self-Talk Positif Untuk Meningkatkan Performa Atlet Basket. Psikologi Udayana, 4(2), 367-378.

Kumalasari, D., Kameliawati, F., Mukhlis, H., \& Krisatanti, D. A. (2019). Pola Menstruasi dengan Kejaidan Anemia pada Remaja. Wellness And Healthy Magazine, 1(2), 187-192.

Latifah, A. N. (2017). Faktor-faktor yang berhubungan dengan perubahan siklus menstruasi pada mahasiswi semester II diploma IV bidan pendidik universitas 'aisyiyah yogyakarta. 5.

Mutasya, F. U., Edison, E., \& Hasyim, H. (2016). Faktor-Faktor yang Berhubungan dengan Usia Menarche Siswi SMP Adabiah. Jurnal Kesehatan Andalas, 5(1), 233-237. https://doi.org/10.25077/jka.v5i1.475

Novziransyah, N. (2017). Pengaruh Budaya organisasi terhadap Kinerja Karyawan PT. PLN (PERSERO) Kantor Wilayah Sumatera Utara Medan. Jurnal JUMANTIK, 2(1), 13-25.

Petiwi, K. R. (2011). Analisis Dan Rekonstruksi Materi Kesehatan. Pendidikan Jasmani Indonesia, 8(April).

Pratiwi, Z. (2017). Hubungan Antara Usia Menarche Dengan Lama Siklus Menstruasi Dan Kejadian Dismenoren Primer Pada Remaja Putri Di Sma Negeri 1 Makassar. 13-14.

Pundati, T. M. (2016). Faktor-Faktor Yang Berhubungan Dengan Kejadian Dismenore Pada Mahasiswa Semester VIII Universitas Jenderal Soedirman Purwokerto. Jurnal Kesmas Indonesia, 08, 40-48. 
Santrock, J. W. (2013). Adolescence.

Sari, C. F. P. (2018). Gambaran Lama Menstruasi Pada Remaja.

Setiya Wahyudi, A., \& Wahid, A. (2016). Ilmu Keperawatan Dasar Buku Ajar.

Trimayasari, D., \& Kuswandi, K. (2014). Hubungan Usia Menarche dan Status Gizi Siswi SMP Kelas 2 Dengan Kejadian Dismenore. Jurnal Obstretika Scientia ISSN. 2337-6120, 2(2), 192-211.

Tsamara, G., Raharjo, W., \& Putri, E. A. (2020). Hubungan Gaya Hidup dengan Kejadian Dismenore Primer pada Mahasiswi Program Studi Pendidikan Dokter Fakultas Kedokteran Universitas Tanjungpura. Jurnal Nasional Ilmu Kesehatan (JNIK), 2(3), 130-140.

Yeni, R. I. (2017). Application of Kathrine Kolcaba 's Comfort Theory on Children Fulfillment of Oxygenation Need in Treatment Rooms. Ejournal.Umm.Ac.Id, 8, 65-73. 